\title{
Title
}

\section{Youth Jury Policy Deliberation: Towards a fair and responsible Internet}

\begin{abstract}
Young people aged between 12 and 17 across three major British cities - London, Leeds and Nottingham - were invited to play the role of 'jurors' on a case where 'the Internet was put on trial'. The recommendations reported in this paper are intended to improve digital experience and online safety as contributions to policy. These recommendations derive from the 'youth jurors' policy deliberations designed to encourage young people to reflect on their digital experience and collectively develop their own problem definitions and solutions.
\end{abstract}

Keywords: Deliberation, Youth, Digital, Rights, Juries

\section{Introduction}

The significant change in children's media consumption time spent online among those aged 12-15 is that it has overtaken television watching (Ofcom 2017). An increase in cyber bullying and sexting mentioned in ChildLine counselling sessions (NSPCC 2016) raises concerns over children's Internet use and safety. So far, policy debates and research on young people's Internet safety (HM Government 2019; Kidron, Evans and Afia 2018; Livingstone, Haddon, and Görzig 2012; Ringrose, Gill, Livingstone, Harvey 2012) are limited by the domination of adult experts and the overwhelming discourse of fear - an emphasis on risks, exploitation and harms- which stipulate the need to guard minors against exploitative practices that make their Internet experience intrinsically risky.

To counter these limitations, the 5Rights charity commissioned Professor Stephen Coleman 1 to devise a method of inquiry to create a space for young people to speak of and critically reflect on the challenges that are important to their daily digital engagement. Prof Coleman and Dr Pothong then developed dramatic scenarios to prompt participants' deliberation and analysed the data collected (Coleman, Pothong and Weston 2018)2. The 108-research participants aged $12-17$, from London, Leeds and Nottingham, were encouraged to exercise their entitlement as democratic civic agents to pass a reflective collective judgement on the problems with their digital experience and possible solutions rather than being mere 
informants in discussions framed by what adult experts think they need. Reflections from personal experience and the resulting recommendations from research participants contradict the dominant discourse of fear, highlighting young people's values for agency, fairness and responsible digital practices.

\section{Space for children in policymaking}

Young people's participation in policymaking is often limited by two factors. One is their status in the adult-child relationship, which undermines the legitimacy of their voice and contributes to power asymmetry in their participation in policymaking (Lansdown 2006; Shier 2010). The other is the incompatibility of the communicative practice and style in the formal decision-making process and that of young people to an extent that excludes their genuine voices (Cockburn 2010). To address these limitations, Mannion (2007), Cockburn (2010) and Hill (2015) suggested developing an adult-child relation and space for young people to legitimately and comfortably speak about who they are and what they need without sacrificing their identity as children.

Agreeing with such suggestion, this research creates a space that supports reflective collective decision-making for this generational group and appeals to their sense of playfulness as well as their chosen mode of expression, emphasising a flexible, inclusive and open-minded communicative style. To build such a space, deliberation, with its potential for open and reflective exchange, is combined with the entertainment, spontaneity, and indeterminacy of drama (live performances of dramatic scenarios).

All youth jury deliberations for this research were filmed and transcribed. These video records and transcripts formed the units of analysis for this research. To evaluate these deliberative decision-making processes and explain the digital world young people seek, inductive thematic analysis, close reading, and a search for key stories, patterns of argumentation and the emergence of recommendations were used. Attention was paid to tracking how the participants came to recognise and define problems and collectively develop recommendations.

\section{Fusing deliberation with drama}

Deliberative theorists such as Dryzek (2009) and Mansbridge et al. (2010) project deliberation as a talk-based process to reach mutually acceptable solutions to social 
problems through an exchange of and reflection on stories, experiences, opinions, argumentation and persuasion. The values and legitimacy of the outcome of this process derive from an exercise of agency, inclusion and consideration of others' ideas and a willingness to yield to or accept a better argument or reasoning in the process. Deliberation presents an alternative to partisan position-taking, the use of aggressive mechanisms to win arguments and the politics of 'winners' and losers' in public decision-making; it creates a space for people to reflect on who they are, what they need, how they might collectively decide on actions to be taken and accounts for all stakeholders.

The application of deliberation with young people in this research provides an opportunity to learn about the way practical reasoning takes place within a generational group that is often dismissed as lacking the sufficient maturity and knowledge demanded in public policymaking. It contributes new systematic research findings on how young people deliberate to two strands of literature. One is the literature on the normative, epistemic and pragmatic value of public deliberation (Steiner 2012; Coleman, Przybylska and Sintomer 2015). The other includes the observational research on how young people talk about political issues (Ekstrom and Ostman 2013; Thorson 2014).

The deliberative exercise for $12-17$ year-olds in this research is designed to help the participants navigate the convoluted process of opinion formation which is often shaped by competing and inconsistent values. To avoid becoming hyper-rationalist, the deliberative model adopted here is one that emphasises self-expression over the normative practices in the typical policy sphere and standard deliberative model that, according to Young (2002, p. 49) and Ruitenberg (2009), tend to favour dry reasoning. Participants are encouraged to draw on their feelings and experience, applying empathetic reasoning rather than objective evidence, statistics or research to win the debate. Participants are reminded that they are engaging in a reflective collective decision-making process that requires both compromise and candour through the metaphorical role of a jury member.

The use of this metaphorical role puts participants in a position of judgement as individuals committed to their own principles, values and interests and as members of a group in pursuit of collective outcomes which may require degrees of compromise. Participants' own descriptions of juries excerpted below demonstrate their understanding that in playing the 
metaphorical roles of jurors they are expected to collectively and responsibly deliver verdicts, in this case, on the Internet.

A: 'the jury of the people in the court'

B: 'a group of people that come up by the decisions and ... talk about something... like a jury that decides whether a person goes to gaol or not, for example...'

To facilitate the jurors' deliberation, dramatic scenarios served two key purposes. The primary point was to dramatise deliberation, offering a sketch of a communicative protocol to this youth jury policy deliberation and easing the challenge of breaking the first word. The other motivation was to serve as a prompter - or vignette - to help participants digest, encourage discussions and reflect on the complex relationships among young people, digital technologies, digital-mediated communication and relevant rights. In this research, dramatic scenarios featured aspects of young people's digital experience that triggered consideration and discussion about fundamental rights, as empowering tools, identified by the 5 Rights initiative3.

Following the tradition of applied drama and drama in education, these scenarios are designed to ease participants into an exchange of their digital experience, which may be frustrating and embarrassing, rather than diving straight in. Vignettes are found to be particularly useful in prompting reflective responses from young people and in discussions of sensitive subjects in various areas, ranging from domestic violence and abuse (BradburyJones, Taylor and Herber 2014) to experience of physical exercise (Yungblut et al. 2012) and perceptions concerning end-of-life care (Gerard 2017).

Storytelling also takes the form of a personal experience that participants are triggered to share by the dramatic scenarios. According to Fischer and Gottweis (2012, p. 13), storytelling in this sense either embodies or supports arguments and provides evidence for claims. It also serves to help youth participants in this research build their experiences into the larger mosaic of a policy debate as part of the deliberative process in which they are involved (Hajer 2003, p. 104). 


\section{Constructing and moderating the juries}

In constructing the youth juries, participants were recruited by the SHM Foundation and Citizen-centric Approaches to Social Media Analysis (CaSMa) through their networks of young people, youth councils and clubs in London, Leeds and Nottingham. Both organisations have been DRB-checked and have extensive experience working with young people.

Participants were given an information sheet, detailing registration requirements, the research objectives, activities, expectations of their participation and how to register their interests. The interests registered were processed, using age and diversity of social background as selection criteria. For this research, the eligible age range was $0-17$, in compliance with the definition of a child in the UN Convention on the Rights of the Child and the UK Children Act 1989. Given the legal status of the participants, interested parties were required to submit a letter of support from a named teacher, youth worker, parent or legal guardian to take part in the jury. Upon confirmation, participants were required to submit an electronic copy of the consent form signed by their parents or legal guardians and hand in the original on the day of their attendance; they were also advised that they were free to leave at any point without consequences.

A total of 107 children aged between 12 and 17 were recruited across London, Leeds and Nottingham. Of the participants, $54 \%$ were female and $46 \%$ were male. In each of these cities, two - four youth juries were held. The juries seated an average of 17-18 youth jurors and took three hours.

Each of these deliberative juries was moderated by a highly experienced individual who had been DRB-checked. The moderator's assignment was to ensure that all participants' experiences, views and recommendations be heard and respected. In these sessions, the moderator asked probing questions and intervened as appropriate, supporting participants to articulate their thoughts, empathetically negotiate their value propositions and arrive at mutually acceptable recommendations. These steps ensured that the deliberative decisionmaking processes did not turn into quests for the 'right answers' and that less confident participants' views were also heard. The power dynamics resulting from differences in ethnicity, religion, gender, age, skills were, thus, neutralised. To assess the claimed benefits 
of deliberation for young people's sense of efficacy, pre- and post- session surveys were administered.

\section{Deliberation in action}

All the deliberative juries opened with a discussion among participants about the importance of particular digital tools, technologies and services. They were also asked how the Internet affected them as individuals and how the rights pertaining digital engagement, or the absence thereof, encroached on their autonomy. The participants were encouraged to focus on their personal experiences before expanding to claims and speculations about young people and the Internet in general.

The participants were then encouraged to deliberate on the ambiguous nature of the Internet, i.e., life-changing yet problematic, and four other particular aspects of digital experience depicted by live performances of dramatic scenarios. The deliberation that followed each of these specific aspects of digital experience featured a four-step process:

1. The storytelling stage featured exchanges of participants' experiences related to issues raised by the scenarios.

2. The problem definition stage focused on particular concerns, leading to problem definition. Here, participants thought about responsibility, accountability and the values and interests involved. This exercise distinguishes this research from other non-deliberative research on young people's Internet experiences because the deliberative approach enables research participants to define their problems and provide responses to such problems rather than responding to researchers' predefined notions.

3. The policy brainstorming stage looked at developing potential solutions and debating their merits. Here, argumentation and persuasion backed by personal experience shifted opinion individually and collectively.

4. The policy sifting and resolution stage shortlisted one or more recommendations that participants thought were related to the problem identified. Here, discussions intensified and shifted more to pragmatic and rhetorical considerations. 
Pragmatically, discussions focused on developing solutions that seemed most likely to be adopted by policy-makers and the digital industry. Rhetorically, argumentation and persuasion were more intensively used to express and promote favoured solutions.

The introductory scenario featured the dubious side of the Internet and triggered participants across all nine juries to discuss their own digital experiences as well as those of people they knew. Subsequently, participants moved from an abstract idea of how the Internet generally affects people in the opening discussion to their actual experience of digital engagement, practical evaluation and reflection on their efficacy as consumers and citizens.

\section{The right to know}

After this introductory scenario and discussion, participants watched a live dramatisation of an online shopping experience. The immediate response featured an increasing unease about the practices of online personal data collection, tracking and storage:

'You wouldn't do this in real life, you wouldn't give someone...you wouldn't give a shop all your card details and let them give it to other shops, so I don't see why it's different online.' (London Jury1)

'I don't think it's quite fair either, because your details are being shared onto other websites without you actually knowing.' (Leeds Jury2)

These comments indicate that young people are quick to discern the difference in standards of practice between online and off-line service providers. These reactions suggest that the jurors feel exposed and vulnerable having realised that their personal information can be tracked, mined, and shared without their consent. In fact, the participants deemed that such practices were 'unfair'; some even suggested a ban on personal data storage and sharing:

'I think that it is important that it's made by law that companies... who give your information to third parties are prosecuted and are sued.' (London Jury2)

As the participants moved toward problem definition, they began to debate whether and under which conditions companies should be allowed to collect personal data. Across all the juries, the debates on these conditions marked the juries' move from the abstract principles of third-party data collection to a more practical mechanism of information management 
through informed consent. This was the point where participants began to re-define what they perceived to be the main problem:

A: If you want to share something, your details, ... it's fine, but you have to be aware of the consequences of that ...

B: I don't think they really ... tell us ... what you're ... signing up for when you sign into the site, so... I think ... they should ... have a list of stuff that you should be aware of before you ... started buying or using the site.

C: Well, to be fair, most of the ... terms and conditions underline that ... the website requests you to ... put in your details ... I think, in most situations... your info can get leaked still...so I think that's like, a breach of someone's trust...

D: I think that many websites ... don't really disclose all the information... They keep all your profile history that you are putting on your Facebook, so they don't tell that but they do that...

(London Jury1)

The comments from this phase of deliberation highlighted scepticism about the transparency of personal data handling by digital companies and the way terms and conditions were worded.

Participants also reflected on their habitual interaction with terms and conditions, finding them incompatible with user behaviours, and found such incompatibility problematic.

A: I don't think anyone can really be bothered to read all the way through. Because sometimes they're like 30 pages long and it's probably just the same on every website...

B: I think they should ... shorten it ... so people can actually be bothered to read them all.

C: I think it should be ... a big requirement ... to have all of these T\&Cs simplified ... and avoid using any over complicated language... I remember ... a few years ago I read about ... this service was from Sony and they slipped, ... in this passage in ... their terms and conditions that ... the person who ... accepted the conditions would legally give them ... their soul.

D: ... the public aren't ... paying much attention to what these ... terms and conditions and that how much of a problem it really is.

(Leeds Jury1)

Such incompatibility, together with the scepticism about the transparency of personal data handling, formed the centre of participants' discussion concerning barriers to their abilities to manage information about themselves. 
The jurors then began to consider possible solutions to this problem and later broke into smaller groups to formulate specific recommendations. This phase featured varying degrees of sophistication in argumentation and recommendation. One jury was pragmatic in its recommendation, based on consumer behaviours:

A: Um, like, define the key points of the terms and conditions... we don't need to take pages and all that ... I mean I'd be quite content with a page of bullet points basically summarising the terms and conditions ... I think I'd read it...

B: They could make the first page the summary and then they could go into more detail after. And you wouldn't have to read the detailed bit. You'd just be able to know what it's about from the summary.

C: Make sure it's easier to read.

(Leeds Jury1)

Other juries offered more creative ideas for making terms and conditions more accessible:

'Video terms and conditions, so it's easier for people to understand and they don't have to read through pages and pages ... because... when someone's reading it to you it tends to be faster and they can process it quicker...' (London Jury1)

Yet another jury suggested a more prescriptive approach to ensure that service providers fulfil their requirement for simple, comprehensible terms and regulations:

'We've got an idea of a moderation board. And basically what would happen is there'd be a group of people that would go through all of the, um, like, terms and conditions. And there'd be a word count on them; and if they went over it they'd have to pay tax on it, because then that would make it worse for business... And, ... make sure someone reads through them all and just make sure there's all the important stuff in there. Because overall you just want people to actually read them and understand what's in them.' (Leeds Jury2)

In developing this prescriptive recommendation, the jurors touched on a number of sophisticated political considerations concerning power relations among users, service providers and government:

A: Do you think that we, the consumers, can make a change then, or do you think it would be something to leave to the Government and the big owners?

B: Yeah, the Government...

C: You haven't much of a say.

D: But I think it's also like the public ... They need to know what they're 
signing up for.

E: I think they should put out regular surveys to actually see what the people want.

A: I think the power that we have is most effective in big groups. So if you complain, ... they'd be polite and probably do nothing about it. ... But ... if a lot of people don't like what they're doing they're going to start failing, so... that's where we would come in.

B: I think that there should be business independence too ... I think you should enforce tax, ... so if they choose to like make the terms and conditions longer, they should have like a tax on it.

(Leeds Jury2)

This consideration and their call for comprehensible terms and conditions for Internet companies' handling of personal data reflect a value for self-efficacy and transparency. This implies the participants' intent to take responsibility for their Internet use.

The richness of deliberation on this scenario confirms that it served well as a stimulus across all juries. There are clear connections between the storyline of the sketch and the participants' experience. Through experience sharing, the problem of personal data collection began to take shape, followed by argumentation and recommendation. By the time participants arrived at their shortlisted recommendations, they had moved quite far from their starting point as audiences watching a dramatic scenario to actively deliberating about their efficacy as both consumers and citizens. Through deliberation, they moved from the abstract principle of privacy to the practical mechanism of consent. In the process, they raised critical questions about government's support for regulation of the digital industry that contributed to a mature and rigorous policy debate.

\section{The right to delete}

The second scenario featured various contestants justifying their desire to remove the content they put online in a game show. This scenario prompted split responses to users' ability to remove unwanted content from the Internet. Some contended that children should take responsibility for the content they put online.

Others believed that young people should be given an opportunity to remove traces of their immature selves. 
'Personally, it's like when you're younger, you'll do things, but you'll look back on it and you'll regret it - and if you regret it that much you should be able to delete it and pretend it never happened...' (Leeds Jury1)

'Well, who you are online isn't really who you are...Y You shouldn't be portrayed by just your social media.' (Leeds Jury2)

Participants took a while to work out the two conflicting moral positions and arrived at a strong consensus on what they thought the problem really was:

'We recognised that almost the biggest problem is information that you've shared being moved onto a different medium...We say the problem occurs when this private message you shared is screenshotted and then given to the wider audience which you didn't, um, consent to. So, you know, that can constitute things like private photos being linked and videos of you being shared that you didn't want.' (Leeds Jury2)

Undeletable content was then identified as a problem by most juries. They associated this issue with the power of digital technologies that allows copies of the original content to be made, stored, and shared virally. This, according to the participants, is a serious problem:

'I have a friend who had a very like private conversation with someone she knows and they actually screenshot the conversation and she mentioned like a lot of embarrassing private things on there. And once he posted it on his own Facebook she was kind of outcast from school and bullied to the extent that she had to move to another school. So I think people need to be well advised on how dangerous it actually is to post something.' (London Jury2)

The participants' experience of sharing that developed into a problem definition concerning screenshotting revealed a risk in children's online experience which remains underconsidered in the existing research (Livingstone, Haddon, and Görzig 2012). From this development emerges a connection between digital technology, the screenshot function, and user practices that young people perceive to be problematic. Participants' description of and focus on screenshot as a problem also serve as a barometer indicating the degree of severity of the problem experienced by young people.

Several juries also expressed frustration about the technical complications in managing duplications and archiving personal materials through screenshotting as well as the circulation of the screenshotted materials. Underlying this dissatisfaction is the uncertainty 
about what could happen to the information that young people put online or information about individuals posted by others.

A: 'I suppose it depends on ... the social network. But, like, Facebook, you've got delete for, like, everything that you do... But if someone takes a screenshot it's like they're on their phone; it's like not connected to the internet in a sense, so like, once it's there..., there's nothing you can do...'

B: 'Yeah, if there's one screenshot of it then it has the potential to go to anyone.'

C: 'Reporting takes like a day before it is down, and by then people have shared it. People have liked it. People have seen it. People have screenshotted it and it's never ... gonna go.'

(Leeds Jury1)

Having defined the problem, participants proceeded to consider mechanisms that would allow them to control and manage the circulation of personally damaging content.

Recommendations from the Leeds and London juries included a requirement for consent from the owner or those featured in the screenshotted content:

A: 'If you want to publish something, you are allowed to, but only if it's your own. If it's with someone else ... you need to have a consent from that person to be able to post ....anything.'

B: 'Yeah then it will have a sign coming up saying will you let this person screenshot ya and then you're allowed to say yes or no before they're allowed to save it.'

(London Jury 1)

To come to terms with this problem, a technical proposal was advanced by the Nottingham Jury2:

'We were talking about tracking photos ... Because if you post a photo on the Internet, or a friend posts a photo of you on the Internet, then they've posted it and that's like an original source. When that's shared, copied, you know, sent to other people, it's all linked. So you've got this one original source and then you've got other sources coming out of it. Then when you go to the original source, or any of the others, you can delete that and it'll delete all the copies. So, it's kind of like... you have to have some way of tracking or following things to be able to keep them under your control ...'

Another jury considered regulatory possibilities:

A: '...what about screenshots. Say it's not Facebook that um you want to report it to, say ... I've taken a screenshot of this picture, and I'm gonna show it to my friends, there is no way to actually regulate that. 
B: 'But you can do that with any other thing.'

(Leeds Jury1)

The technical recommendation offered by the Nottingham jury, though creative, is limited in terms of its practicality. The Leeds jury's consideration of regulatory possibilities was inconclusive. Despite their limitations, both efforts indicated a desire for control over personal materials and more responsive interaction with the technology used. The persistent lack of uncertainty concerning an effective mechanism to manage duplications, archiving and sharing of personal materials would leave participants feeling very vulnerable online.

\section{The right to safety and support}

The third scenario portrayed a young person with social media addiction. This scenario appeals to the participants on an emotive level, prompting the participants to share experience of the impact of their dependence on digital technologies:

'I personally find it quite hard to stop checking social media, as I'll check Twitter and then I check Instagram and then I'll check Facebook and then I'll leave it and then I'll go back to Instagram and then check Facebook ... you always want to see the next update on it. And I think that that's quite bad because we're all becoming very reliant on it and I think that if they were taken away we'd actually realise that we have a lot more time because most of its spent looking down at apps.' (London Jury1)

The participants' responses to this dramatic scenario show that they recognise the vulnerabilities that make them prone to addiction. The accounts of their experience also demonstrate that they struggle to exercise their right to agency - an ability to disengage at will. The recognition and struggle to exercise agency shaped their problem definition.

As the participants were formulating problem definition, two competing arguments emerged: 1) young people should take responsibility for their own behaviour by exercising self-control and 2) everyone in society, particularly the digital industry, is responsible because the problem is culturally induced.

'...I think the problem is that nowadays everyone sees...immediacy in everything so for example if someone texts you, you feel like you have to reply instantly. Whereas actually you... don't... we need to just turn off and that is a problem that we can't...' (London Jury3) 
'... free mobile games, they're designed so that, they're there for replayability ... um, and it's got to the point where you become so invested into the game where you're willing to put some money into it and you, and that's where, like, um, companies ...that make free games...get their main, sort of, income from, where they make it, um addictive enough so they're the one that benefits from it ...' (London Jury4)

Both comments reflect participants' perceived social pressure. The latter, highlighting strong cynicism toward digital companies and the conflicting interests of users and those of digital commerce, added a political flavour to this phase of the deliberative process.

Having identified responsibility from all relevant parties as an issue, the participants explored possible solutions. The idea of a tool that set 'time limits' on Internet and other digital technology usage appealed to many juries. The concept of accountable adults to curb young people's dependence on digital technologies was also considered:

A: I know the reason why my mum started to take my phone off me was because I'd get nasty texts or whatever that would actually stop me sleeping. ... It was just so I couldn't get nasty texts before I went to bed.

B: They could make an app that locks Facebook or Twitter.

C: You could set it to a time.

B: Because they do on X-Boxes and things... where they can say it switches off at this time...

D: It's the parents ... what the parents decide.

A: But then, is that fair on the child ... if their parents aren't as responsible as perhaps other people's?

C: Or like the children like me in care.

B: If they're in care, then who's gonna take that responsibility for them? ... Because if the parents don't want to take responsibility, then the children aren't going to.

A: If the child realised that they're not getting enough sleep, they could do it themselves and make is so it locks out automatically at a certain time.

D: Or you could say to someone, can you do it for me? Put a password on it. 
This phase of deliberation concluded with proposals for 1) time limits for Internet use to help young people exercise self-control and manage social pressure and 2) online support for young people who feel trapped in digital networks.

\section{The right to informed and conscious use}

The fourth scenario featuring a negative effect of social pressure suffered by a young person in her digital engagement provoked a reaction, triggering rich experience sharing:

'Sometimes looking at peoples' newsfeed ... is slightly depressing. My best example is after being bullied in key stage 3, I've gone on to make a couple of more friends ... and then I heard that they were going to see the ... the new Hunger Games film, and the only way I found out about it was on Facebook after they'd been... it's sometimes depressing because you think, 'Oh, I would have wanted to come to that'.' (London Jury2)

'I feel like you have an increased anxiety whether you're doing enough now because you see people going to parties, going out or doing revision and you think, 'Oh, they've done six, I'll have only done four'. And you always, kind of, compare yourself to the average. Like, you create a fake average in your head.' (London Jury4)

Unlike other scenarios, participants' initial responses were dismissive of the effects of social pressure, taking it as a non-problem. Some deemed that people's accounts of their lives on social media tended to be 'showing off' rather than reality:

'Some people just use like Facebook and Instagram and things like that just to promote how good their life is and make it seem much better than it actually is and make other people ... feel really bad.' (London Jury1)

Others thought that the character in the scenario should be less sensitive:

If you see something online ... your friends are at a party and you're not ... don't over-analyse it... I think people are making themselves feel like the way they do...It's just a picture of someone having fun...I think it's down to the people who are looking at it and getting upset by it. (Leeds Jury2)

However, empathetic reasoning is one of the products of deliberation. The more participants thought about the initial dismissals, the more they began to reconsider. It is worth noting that what seemed to be apathy at the beginning could have been a defence for their vulnerabilities - avoidance of exposing their own hurt feelings - although it was difficult to gauge how many of the participants had such emotions. 
With increased empathetic reasoning, the participants started to discuss the pressure that 'some people' might be experiencing and developed recommendations accordingly. They attempted to discern whether this was specifically an online problem or a general problem that transcends the artificial online - offline boundaries:

A: But is there anything to do with the Internet itself or is that just people?

B: It's just people.

C: No, I think it makes it worse... just search through twitter feed for depressed girls or suicide. There's a massive group of teenagers and they're just surrounded with the same ideas and the same values and those are the only people they feel that they can relate with.

B: You get sucked into online.

C: Yeah, exactly ... and when people start to notice it then, they're so different that we literally can't rescue them and we can't save them and they harm themselves and it just makes me hurt.

(London Jury3)

This discussion demonstrates that participants perceived social pressure as a problem of general human behaviour amplified by digitally mediated communication. This perception reveals that given an appropriate environment and stimulus, children can digest and dissect quite complex relationships among themselves, others and digital technology.

With empathetic reasoning and recognition of the artificial online - offline dichotomy, participants proposed provisions of support for vulnerable people and mechanisms for counter-balancing social competition:

'Charities like Childline and Samaritans need to have more presence online and be able to talk to people... you can see Adidas adverts on your Facebook page like three times a day, but you hardly ever see Childline or Samaritans or charities that you can talk to.' (London Jury3)

'... whenever you log onto Facebook, you have to write down the things you like about yourself that day ... something that's made you feel good ... Because then it would boost you up a bit.' (Leeds Jury1)

Unique when compared to other scenarios, this one triggered a great deal of account sharing and identification with the situation and emotional impact depicted in the scenario. However, the participants were reluctant to regard such a negative effect as a problem worthy of policy attention. Although it took quite a lengthy deliberation to shift and soften 
the participants' initial apathy, eventually more empathetic reasoning was achieved. This triggered significant changes in the way problems and solutions were framed and defined. The shift in perspectives here is greater than the shift observed in other scenarios.

\section{Policy implications}

The quality of deliberation and recommendations from the participants demonstrates that given the space for open and reflective exchange that young people feel comfortable in, they can realise their often misjudged capabilities of reflective and collective problem-solving in the way adults are assumed to be able to. The research participants reported an increased level of confidence as social actors. Such increased efficacy at the policy level suggests that minors can contribute to public policy development as active agents as well as informants.

This increased sense of efficacy is observed in the pre- and post-session survey results. In their pre-session survey, 36 out of 104 participants stated that they had 'no say' on 'how the digital world works'. In the post-session survey, 77 participants rated their agreement at the scale of 5 (out of 10, with 10 being completely agree) or over to the statement that they are 'confident that they can influence the way digital technologies work for young people'.

The use of deliberation and drama in this research enabled young people to master a form of civic language, manifesting in articulations of their rights and calls for actions, based on reflective collective problem-solving. The collective problem-solving process legitimises young people's contribution to more targeted policy development. The increased efficacy of adolescents as social agents through deliberation challenges the domination of 'adult experts' and the discourse of fear in policy debates and research on young people's Internet usage.

The problem definitions and recommendations developed by youth research participants in this research show that young people are primarily interested in moral consistency between the online and offline worlds and sensible, pragmatic regulations. They anticipate mechanisms that empower them to take greater control over and responsibility for their actions. This expectation of online-offline moral consistency renders any policy frameworks based on the limited rationale of 'online solutions' irrelevant because these young users do not distinguish between online and offline worlds. They see both as indispensable aspects of social reality with the same rights and responsibilities. They also perceive online norms that 
are inconsistent with offline norms as injustice, highlighting that young people take the notion of fairness in everyday life very seriously.

The transcendence of the online - offline dichotomy is vividly reflected in the participants' reaction to and deliberation of personal data and the right to delete reputation-damaging content. The participants quickly recognised that when they went shopping with their parents it was not acceptable for shopkeepers to collect children's personal data or track their purchasing habits, let alone pass on their details to other businesses. They regarded such online practices as the breach of an off-line moral standard and deemed the practice problematic. Likewise, whilst recognising that they had to take responsibility for their online actions, they were aware that in the offline world people were given opportunities to repair the effects of their ill-considered actions. They therefore asked for mechanisms to take better control and responsibility for their online actions.

The idea of government regulation in general did not appeal to these young participants. However, they did not completely reject regulation. The analysis of the youth jury deliberation indicates that young people favour regulations that enable them to negotiate structures of power and behavioural norms in their digital engagement just as they can in any other social spaces. They tend to consider regulation as an option to rebalance power, compelling digital companies to adhere to reasonable norms and fair practices. This preference suggests that regulations that feel like imposition and restrict young people's exercise of agency are likely to be rejected. It also means that policies that are dominated by safety agendas are likely to be incompatible with young people's needs.

\section{Conclusion}

The problem definitions and resolutions developed by the youth juries as well as the resulting policy implications highlight the strength and benefits of the combined method of drama and deliberation in eliciting people's values and preferences. The strength of this method lies in its ability to empower youth participants to develop a kind of civic language based on their feelings and sensations as triggered by the dramatised relatable experiences with aspects of the digital world and on rationality as well as imagination. The spontaneity and indeterminacy of drama in the scenarios served as a means to ask questions about young people's Internet experience without the pejorative framing of existing discourse concerning their online experience. The four-step process of deliberation gave a clear purpose for young 
people's reflective responses to define problems and solutions based on their attitudes, knowledge, skills and experience.

This combined approach shifts the resulting problem definitions and recommendations from the discourse of fear to one of aspiration to exercise agency. This shift away from the discourse of fear demonstrates that a combination of inquiry methods is an effective tool for listening and talking to young people. Such approach can be applied to other policy areas to elicit authentic voices from people rather than voices filtered through the problem framing of adult researchers, experts and policymakers. The approach has successfully been applied and adapted in policy research, design and development concerning Internet enabled and autonomous technologies (Pothong et al. 2019; Pschetz, Pothong and Speed 2019) to obtain insights into people's acceptability factors.

One limit of this approach is tied to its resource intensiveness, which can restrict the number of research participants. A great deal of care and time has been invested in designing, developing and refining the dramatic sketches to weave in without prejudice the issues in question, in this case, user online activities, cultivated dependence, unwanted content, data collection and processing. Also, to ensure the quality and depth of the deliberation, the number of participants per each deliberative session is limited to a maximum of 20. Scaling up the number of participants would require more time. However, the limit in terms of number of participants can be counter-balanced by the relatability of experience. Despite such limitation, findings from this research are generalisable in principle on grounds that those with similar attributes and resources who are exposed to similar experiences are likely to come up with similar problem definitions and solutions.

In fact, the request for young people to have information about them removed is now granted by both the UK Data Protection Act 2018 and the EU General Data Protection Regulation (GDPR), provided that there are no legitimate grounds for retaining the data. The juries' core interest in maintaining moral consistency between the online and off-line worlds is supported by the principle of 'parity' in the House of Lords Select Committee on Communications report: Regulating a Digital World (2019: 15). In this report, 'parity' is defined as 'the same level of protection [to be provided] online as offline'. This aligned principle of parity emerged from the deliberation concerning personal data and the right to delete. The principle of 'ethical design' in the House of Lords record (ibid: 19) also has the 
potential to address the juries' concern pertaining to digital products and services that are designed to cultivate dependence or encourage addiction. The report recommends that online services hosting user-generated content be subject to a statutory duty of care based on 10 principles, including the two aforementioned ones and a new independent regulatory body: the Digital Authority.

Subsequently, the Government published its Online Harms White Paper, establishing a new statute of care 'to make companies take more responsibility for the safety of their users and tackle harm caused by content or activity on their services' (HM Government 2019: 41). The overall objective of this White Paper is in alignment with the juries' preferred purpose of regulation - to compel companies to adhere to reasonable norms and practices. However, the scope of harm (ibid: 31 ) to be addressed by regulation does not seem to cover the design of the digital services which supports cultivation of dependency and exacerbates social pressure.

Despite the alignments of these policy and regulatory responses with the juries' findings, the discourse of fear persists in policy debates, just as harms online continue and are increasingly reported. The discourse, backed by actual online harms, has gained political support for regulatory intervention. However, an over-emphasis on the fear factor could risk side-lining the juries' values for agency and preferences for practical mechanisms (i.e., online features) that better support and foster young people's responsible exercise of agency. Further work is required to advocate these values and preferences of young people in the policy arena.

\section{References}

Bradbury-Jones C, Taylor J, Herber OR. 2014. Vignette development and administration: a framework for protecting research participants. International Journal of Social Research Methodology 17: 427-440.

Cockburn T. 2010. Children and deliberative democracy in England. In A Handbook of Children and Young People's Participation: Perspectives from Theory and Practice. Percy-Smith B, Thomas N (eds.). Routledge: Oxon; 328-339.

Coleman S, Przybylska A, Sintomer Y (eds.), 2015. Deliberation and Democracy: Innovative Processes and Institutions. Warsaw Studies in Politics and Society. Peter Lang. Coleman S, Pothong K, Weston S. 2018. Dramatizing deliberation: a method for encouraging young people to think about their rights. Journal of Public Deliberation 14: $1-15$. 
Conrad D. 2004. Exploring risky youth experiences: popular theatre as a participatory, performative research method. International Journal of Qualitative Methods 3: 12-25.

Dryzek JS. 2009. Democratization as deliberative capacity building. Comparative Political Studies 42:1379-1402.

Ekström M, Östman J. 2013. Family talk, peer talk and young people's civic orientation. European Journal of Communication 28: 294-308.

Fischer F, Gottweis H. (eds.). 2012. The Argumentative Turn Revisited: Public Policy as Communicative Practice. Duke University Press: Durham; 328-339.

Gerard N. 2017. Can millennials talk about death? Young adults' perceptions of end-of-life care. Journal of Health Administration Education 34: 23-48.

Hajer M. 2003. A frame in the fields: policymaking and the reinvention of politics. In Deliberative Policy Analysis: Understanding Governance in the Network Society.

Hajer M, Wagenaar H (eds.). Cambridge University Press: Cambridge.

Hill L. 2015. 'Don't make us talk!': listening to and learning from children and young people living with parental alcohol problems. Children \& Society 29: 344-354.

HM Government. 2019. Online Harms White Paper. White Paper CP 57. Available at https://assets.publishing.service.gov.uk/government/uploads/system/uploads/attachme nt_data/file/793360/Online_Harms_White_Paper.pdf [Accessed 29 April 2019].

House of Lords Select Committee on Communications. 2019. Regulating in a Digital World. House of Lords Select Committee on Communications. House of Lords: London, 85 pp. Available at https://publications.parliament.uk/pa/ld201719/ldselect/ldcomuni/299/299.pdf [Accessed 29 April 2019].

Kidron B, Evans A, Afia J. 2018. Disrupted Childhood: The Cost of Persuasive Design. 5Rights, 47 pp. Available at: https://5rightsfoundation.com/static/5Rights-DisruptedChildhood.pdf [Accessed 29December 2015].

Lansdown G. 2006. International developments in children's participation: lessons and challenges. In Children, Young People and Social Inclusion: Participation for What? Davis J, Hill M, Tisdall K, Prout A (eds.). Policy Press: Bristol; 139-156.

Livingstone S, Haddon L, Görzig A. 2012. Children, Risk and Safety on the Internet: Research and Policy Challenges in Comparative Perspective. Livingstone S, Haddon L, Görzig A (eds.). Policy Press: Bristol.

Mannion G. 2007. Going spatial, going relational: why 'listening to children' and children's participation needs reframing. Discourse: Studies in the Cultural Politics of Education 28: 405-420.

Mansbridge J, Bohman J, Chambers S, Estlund D, Føllesdal A, Fung A, Lafont C, Manin B, Mart_1 JL. 2010. The place of self-interest and the role of power in deliberative democracy. Journal of political philosophy 18: 64-100.

NSPCC. 2016. How safe are our children? The most comprehensive overview of child protection in the UK. Available at: https://www.nspcc.org.uk/globalassets/documents/research-reports/how-safe-childre n-2016-report.pdf [Accessed 15 March 2018]. 
Ofcom. 2017. Children and Parents: Media Use and Attitudes Report. Available at https://www.ofcom.org.uk/_data/assets/pdf_file/0020/108182/children-parentsmedia-use-attitudes-2017.pdf [Accessed 15 March 2018].

Pothong K, Pschetz L, Watson J, Gbadamosi J, Asaturyan A. 2019. Making IoT security policies relevant, inclusive and practical for people: a multi-dimensional method. In Living in the Internet of Things: Realising the Socioeconomic Benefits of an Interconected World. Living in the Internet of Things: Realising the Socioeconomic Benefits of an Interconected World. IET: London.

Pschetz L, Pothong K, Speed C. 2019. Autonomous Distributed Energy Systems: Problematising the Invisible Through Design, Drama and Deliberation. In Proceedings of the 2019 CHI Conference on Human Factors in Computing Systems. ACM (CHI '19): New York, 387.1-387.14.

Ringrose J, Gill R, Livingstone S, Harvey L. 2012. A qualitative study of children, young people and 'sexting': a report prepared for the NSPCC. http://www.nspcc.org.uk/

Ruitenberg CW. 2009. Educating political adversaries: Chantal Mouffe and radical democratic citizenship education. Studies in Philosophy and Education 28: 269-281.

Shier H. 2010. Children as public actors: navigating the tensions. Children \& Society 24: 2437.

Steiner J. 2012. The Foundations of Deliberative Democracy: Empirical Research and Normative Implications. Cambridge University Press: Cambridge.

Thorson K. 2014. Facing an uncertain reception: young citizens and political interaction on Facebook. Information, Communication \& Society 17: 203-216.

Young IM. 2002. Inclusion and Democracy. Oxford University Press: Oxford, UK.

Yungblut HE, et al. 2012. Understanding physical activity through the experiences of adolescent girls. Women in Sport \& Physical Activity Journal 21: 3. 